\title{
Thermal and Morphological Study of Blends of LLDPE/iPP.
}

\author{
F. Díaz V. , C. Urbina de Navarro*, A. Müller ${ }^{* *}$ \\ *Universidad Central de Venezuela, Facultad de Ciencias, Centro de Microscopía Electrónica, \\ Caracas, Venezuela \\ ** Universidad Simón Bolívar, Departamento de Ciencia de los Materiales, Grupo de Polímeros, \\ Caracas, Venezuela
}

Modification in the crystallization of dispersed phase of a polymer in other are known as fractionated crystallization, it is presented as consequence of the fine dispersion of a crystallizable polymer (isotactic polypropylene, iPP) in an immiscible amorphous matrix. It can be demonstrated that a new cryatallization process develops at lower temperatures than those typically encountered in heterogeneously nucleated iPP if the number of dispersed iPP particles is greather than the number of heterogeneities originally present in the bulk sample[1].

Blends of linear low density polyethylene/isotactic polypropylene, LLDPE/iPP (80/20), present fractioned crystallization and still when these polymers are inmiscible the blend can be considered as compatible because of the great physical attraction among the phases; LLDPE/iPP has attractive mechanical properties and varied applications. In this work it was used Differential Scanning Calorimetric (DSC) and Transmission Electron Microscopy (TEM) to investigate the dispersion in the LLDPE/iPP blend. The materials used were LLDPE $(0,92$ $\left.\mathrm{g} / \mathrm{ml}^{3}\right)$, iPP $\left(0,91 \mathrm{~g} / \mathrm{cc}^{3}\right)$ and $80 / 20$ blend of (LLDPE/iPP). The polymers were blend manually before being fed in an extruder double screw.

All the samples were prepared by the Bassett technique followed by replica [2], and by the Montezinos technique [3] for TEM studies.

Results allowed to observe good adhesion between both polymer, the matrix of LLDPE and he dispersed phase of iPP, this adhesion can be explained by the existence of nucleating processes of the iPP on the LLDPE, no separation between the matrix and the dispersed phase was observed as is shown in figure 1. In the figure 2 lamellae are observed among both phases and its characteristics correspond to LLDPE.

The pure iPP crystallizes to $108,1{ }^{\circ} \mathrm{C}$ while it crystallizes in the blend in a fractional way to $101,9^{\circ} \mathrm{C}$ and $86,5^{\circ} \mathrm{C}$, this is corroborated by TEM when determining that the thickness lamellae of the pure iPP are up to $114 \AA$ while the thickness lamellae of the iPP in the blends reach up to $50 \AA$. The difference among the thickness obtained for the pure iPP and for the iPP in the blends reveals that the iPP when being dispersed in the matrix of LLDPE presents the phenomenon of fractionated crystallization, that which also leans on DSC analysis of the blends LLDPE/iPP.

Table 1 summarize the thermal properties of the samples. It is observed that pure LLDPE begins to crystallize to $104,3{ }^{\circ} \mathrm{C}$ while in the blend the crystallization begins to $110,4{ }^{\circ} \mathrm{C}$. It can be to be attributed to the effect of the iPP on the LLDPE because the temperature onset (Tonset) of the blend is higher than the Tonset of the pure LLDPE and lower that the Tonset of the pure iPP. 


\section{REFERENCES}

[1] H. Frensch et al, ACS Symp Series, 395, 1989, 101.

[2] R.H. Olley et al., J. of Polym Sce: Polymer Physics Edition, 17 (1979) 627.

[3] D. Montezinos et al., J. of Polym Sci: Polymeric Letters Edition, 23 (1985) 421.

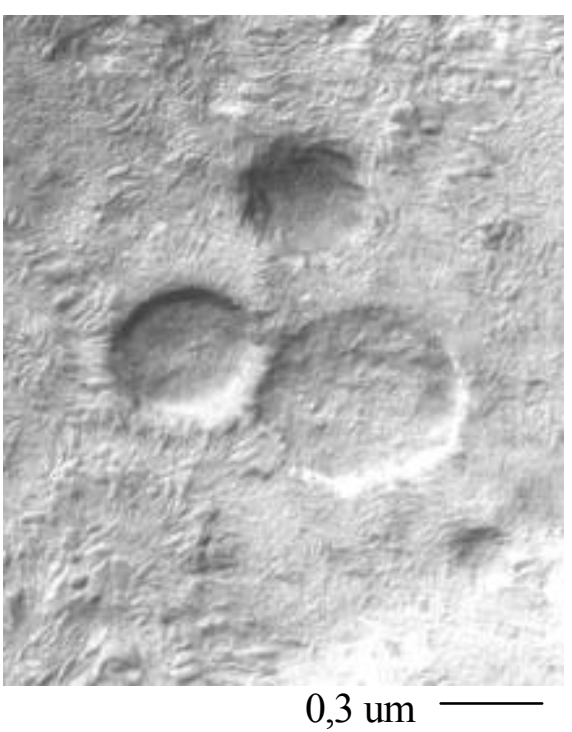

Figure 1. TEM permanganic etching followed by replication, LLDPE/iPP

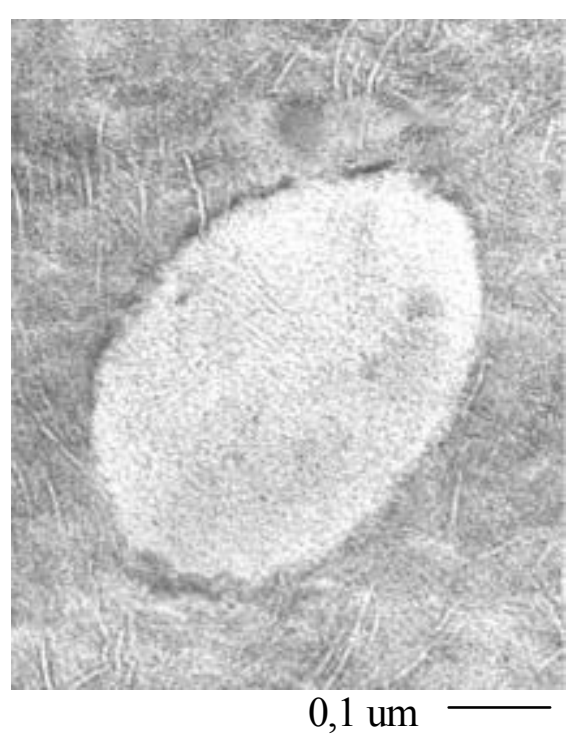

Figure 2. TEM using $\mathrm{RuO}_{4}$ stain, LLDPE/iPP

Table 1. Crystallization data from D.S.C.

\begin{tabular}{cccccc}
\hline Samples & $\begin{array}{c}\mathrm{T}_{\text {onset }} \\
\left( \pm 0,1^{\circ} \mathrm{C}\right)\end{array}$ & $\begin{array}{c}\mathrm{Tc} \\
\left( \pm 0,1^{\circ} \mathrm{C}\right) \\
\mathrm{I}\end{array}$ & $\begin{array}{c}\mathrm{H}_{\mathrm{c}} \\
(\mathrm{J} / \mathrm{g})\end{array}$ & $\begin{array}{c}\mathrm{Tc} \\
\left( \pm 0,1^{\circ} \mathrm{C}\right) \\
\mathrm{II}\end{array}$ & $\begin{array}{c}\mathrm{H}_{\mathrm{c}} \\
(\mathrm{J} / \mathrm{g})\end{array}$ \\
\hline iPP & 119,9 & 108,1 & $-96,1$ & & \\
LLDPE & 104,3 & 100,9 & $-116,8$ & & \\
LLDPE/iPP & 110,4 & 101,9 & $-111,4$ & 86,5 & $-6,8$
\end{tabular}

